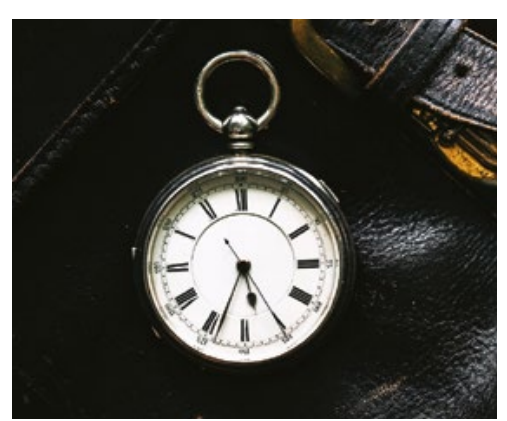

\title{
Ten tips for becoming a Time Lord
}

TEN YEARS AGO we published a blog that summarised our tips for becoming a 'Time Lord' (Box 1). ${ }^{1}$ Most of us can recall colleagues who rarely run late and yet seem to meet all their patients' needs. These doctors are Time Lords. In this article we update our tips to help you to become a Time Lord. The tips outlined in this article are our opinions for you to consider and we would love to hear if you have others.

Extended time in the waiting room recurs as the most important cause of dissatisfaction for patients with a visit to their general practice. ${ }^{2-5}$ In a European study of 10 countries, ${ }^{4}$ time in the waiting room was rated with the least satisfaction. A US study ${ }^{3}$ found that time in the waiting room was inversely associated with satisfaction with the GP. On the other hand, time with the doctor had a major corrective influence on satisfaction. Long waits and short consultations resulted in most dissatisfaction, while long waits for a longer consultation were associated with improved satisfaction. The highest satisfaction was associated with short waits ( $<15$ mins) and reasonable consultation length (>10 mins).

Running late from time to time is inevitable. General practice is unpredictable, which is part of its fascination. However, some of us always seem to run late, which suggests a system problem. Time Lords, on the other hand, seem to inhabit a different space-time plane. While dealing with patients' priorities, they avoid appearing rushed. Time Lords seem to have more satisfied patients. They seem more relaxed at work and so are better able to concentrate on the person in front of them. Their reception staff are less frazzled. Their waiting rooms can have fewer chairs. And they eat lunch.

Here we have reconsidered our tips after another decade of thinking and experience. We have re-ordered them chronologically, considering some as preparation for a session of consulting and others as relevant to the consultation itself. It is clear that some changes to achieve running on time require more fundamental changes to practice systems and so are less in the control of individual practitioners. Some of these organisational aspects we have dealt with in detail in subsequent articles, which are referenced. ${ }^{6-8}$ Tips relating to those organisational aspects we have de-emphasised or removed. We have taken the original 12 tips and, from our experience, added, subtracted and compressed them into the 10 described below.

\section{Preparing}

\section{Fifteen minutes late is not early}

Running on time starts with an attitude. Will you commit to being on time? This means getting to work before the first appointment. Years of running late can desensitise us to the issue. We can feel like being only 15 minutes late is doing pretty well. Time for a coffee and a rest! Will we place as high a priority on calling the patient in on time as they do?

\section{Do the warm-up}

Prepare for the day so you can hit the ground running. Desk tidy? Computer on? 


\section{Box 1. Becoming a Time Lord (2008)}

1. Fifteen minutes late does not mean you are early

2. Work your appointment book

3. MaxPack

4. Control the patient's list

5. Use the annual check

6. Get in the red zone - use your practice teams

7. Engage the patients in the process

8. Breaking up is hard to do

9. Make waiting time productive

10. Group your 'care-families'

11. You gotta dance with them what brung ya

12. Pain is inevitable. Suffering is optional

Logged in? Appointment diary scanned? Every second lost in each consultation adds up. Thirty seconds wasted looking for pathology request paper or refilling the script print bin per consultation adds up to 15 minutes at the end of a full day. Spend time at the beginning of the day checking you have everything you need. Are there plenty of otoscope tips, a jug of water, and enough alcohol swabs? Put as much as you can within reach so that every possible second is valued. Where can you save time? Can you use window envelopes so that you don't need to write the specialist address on the envelope? Is the antenatal share care protocol filed just to hand when you need it?

\section{Work the diary}

The need to see patients urgently when you are fully booked will throw your schedule, and is completely predictable. There actually is no such thing as a 'squeeze in' or a double booking. Only a real Time Lord can bend time or be in two places at once. By thinking about your diary in advance and working with your nursing and reception team, you can prepare for the demand that is coming.

Obvious tips include making sure you have plenty of unbooked appointments on a Monday (demand is always highest when catching up from the weekend) and starting every day with $30 \%$ of appointments free to accommodate urgent appointments (a rough rule of thumb).
It may increase efficiency and timeliness if you consider your patient presentations in two broad families: acute and non-acute. Patients requiring acute care are less concerned about seeing a particular doctor and are more tolerant of some waiting. Non-acute patients are often dealing with follow-up of issues, and chronic and complex conditions. Continuity is more important to them and while they are quite content to wait weeks for a scheduled appointment, they may be more frustrated by long waits in the reception area.

Many practices run a 'jeopardy doctor' system in which one doctor each session is 'on call' to take all acute presentations. This allows the other doctors to focus on non-acute patients without interruptions. Continuity with an individual clinician can be maximised as well as booked team care with nurses, diabetes education and others.

There is a lot you can do as a practice to improve capability to meet patient demand on time. We have gone into some detail on this topic in our other articles. ${ }^{6-8}$

\section{Weight the wait}

Can you add value to the wait time? Can the practice nurse take a blood pressure, collect and test urine or prepare request forms? Can any preventive issues, such as diabetes tests or screening tests, be discussed or ordered while the patient waits? Is there information your patient can read or provide while they wait? All of these can save time when the patient is with the doctor and can be used either for other activities or to catch up.

\section{Consulting}

\section{The golden minute}

Baker, Cordaro and Platt ${ }^{9}$ tell us that the first seconds of an interaction with a patient are golden for creating (or harming) trust. They describe nonverbal cues that can increase oxytocin release and trust in patients: eye contact, warm vocal tone, touch, a smile and an equalising body posture. The 'golden minute' can begin, before calling the patient, with a 10-second meditation. This can be a good investment to ensure our nonverbal cues are right to maximise the effectiveness and efficiency of our interactions. A Time Lord appears focused, not rushed!

\section{Get the agenda}

How many times have you dealt with the first issue thoroughly only to find that there was another and another even more important? And then, with the hand on the door handle yet another!

There is some evidence that if you keep silent initially, the patient will keep talking until they have told you most of what they have come for. ${ }^{10,11}$ Don't panic, most will stop talking within 60 seconds, and probably all by 150 seconds. Try then to extract anything not yet mentioned. A colleague teaches his registrars to ask 'Is there anything else? Is there anything else? Is there anything else?' until there isn't anything else. If the patient comes with a written list, it is even better! You have the opportunity to 'control the list', get hold of it and record the agenda in the clinical record.

A few years ago a colleague added a key strategy for us, which revolutionised our approach to managing the consultation agenda. He advised we ask the patient to prioritise the list. Which issues are most important to them? Which issues must be dealt with before the consultation is over today? Once we know the patient's priorities, we can become more patientcentred in our responses, meeting the pressing need and confidently postponing less urgent issues.

\section{MaxPack}

'Do today's work today'. ${ }^{12}$ Wherever possible, do as much as you can in this visit. This will provide value to the patient as well as reducing the need for a repeat visit. By doing this you preserve future capacity, which helps you to run on time tomorrow. If we ask people to come back unnecessarily, we waste their time as well as blowing out the queue for an appointment. Some have advocated an approach of confining the agenda to only one problem per consultation. We recommend the opposite. In the US they call this 'MaxPacking'.

\section{Red zoning with teams}

The 'red zone' is the high-value time that a patient spends dealing with their 
issues with the clinician they have come to see. On the other hand, time consumed by standing in line, finding the patient, waiting while they find your door, replacing batteries, and answering the phone during the consultation is well outside the red zone. Just an average of two minutes added to each consultation cycle makes you an hour late by closing time!

Red zone time can be increased by making sure other team members are working to the top of their training. Immunisations and cervical screening have long been done by suitably trained nurses and there is evidence that chronic disease care can be well done by pharmacists and nurses. ${ }^{13}$ Measuring blood pressures, checking weights, organising referral bookings, checking on preventive care and even calling the patient into the room can all be carried out by the most appropriate member of the team. While initiating these changes may be a whole-of-practice strategy, it is likely that even within existing work processes you can learn to delegate more, which may increase your 'red zone' time.

\section{Harness the patient}

Some have said that our patients are the great neglected resource for improved healthcare. One of us found that consultations simply ran overtime and that it was in part due to his difficulty in finishing the interaction. The penny started to drop that by privileging the current patient, the next one was being robbed of the opportunity to be on time. It seemed rude to call an end and patients didn't seem to know when the time was up. The '12-minute slip' was created (Box 2), which for two weeks was handed to each patient when they presented to reception. This engaged the patient in the issue of on time running in a positive way and was remarkably effective reducing lateness by $50 \%$. Patients began to watch the clock, noting that we had used our time, and suggesting it was time to finish.

\section{Truth in advertising}

In the end it pays to be realistic. You have implemented the nine tips above, but regularly, by $3 \mathrm{pm}$, you are running half an hour late. Consider blocking out the
3:00 pm and 3:15 pm appointments to make them unavailable for booking and then add another two at $5.00 \mathrm{pm}$ and $5.15 \mathrm{pm}$. These will be at the time you actually see people, not the fantasy time you hope to see them. The result is the same number of consultations occurring at exactly the same time as they always have. The difference is that you have seen everyone at the time they booked.

\section{Conclusion}

Speaking of their previous doctor from a neighbouring, under-doctored town, a patient once said to us, 'I never waited for less than three hours to see him and I never saw him for more than three minutes!'

Waiting in general practice is sometimes unavoidable. Our patients accept this and we need to also. Nevertheless, it is clear that some of the waiting is due to the systems and processes we have in our practices and can be reduced by changing them. There is much we can do as individual practitioners to reduce waiting time. This will increase our patients' satisfaction as well as improving our own enjoyment of work. One of the joys of practice is the lessons we learn from each other. We hope you will benefit, as we have, from considering our colleagues who have become Time Lords.

\section{Authors}

Andrew W Knight MBBS, MMedSci(clinepid), FRACGP, FAICD, Staff Specialist and Conjoint Senior Lecturer, The Fairfield GP Unit, South West Sydney Local Health District, University of NSW; Chair Nepean Blue Mountains PHN, NSW. awknight@aapt.net.au Tony Lembke MBBS, FRACGP, FACRRM, GP, The Alstonville Clinic, NSW; Chair North Coast PHN, NSW

Competing interests: AWK is a member of the editorial advisory board for Australian Journal of General Practice.

Provenance and peer review: Commissioned, externally peer reviewed.

\section{References}

1. Lembke T. Becoming a Time Lord. Alstonville, NSW: Practice Improvement, 2008. Available at http://practiceimprovement.com.au/2008/07/ becoming-a-time-lord [Accessed 11 October 2017].

2. Sebo P, Herrmann FR, Bovier P, Haller DM. What are patients' expectations about the organization of their primary care physicians' practices? BMC Health Serv Res 2015;15:328. doi: 10.1186/s12913015-0985-y.

\section{Box 2. The 12-minute slip}

You may have noticed we often run late ...

Being late is annoying for patients and stressful for staff. We are keen to fix our continual lateness. One of the problems is that our consultations are running over time. Just four minutes extra per consultation means that the doctor is an hour late at the end of the morning.

You can help by:

- being aware that your time with the doctor will be about 12 minutes

- being understanding if the doctor suggests you come back to address remaining issues

- organising a list of issues you wish to cover before you go in.

Please return this slip to the receptionist when you have read it.

3. Anderson RT, Camacho FT, Balkrishnan R. Willing to wait?: The influence of patient wait time on satisfaction with primary care. BMC Health Serv Res 2007;7:31.

4. Grol R, Wensing M, Mainz J, et al; European Task Force on Patient Evaluations of General Practice Care (EUROPEP). Patients in Europe evaluate general practice care: An international comparison. Br J Gen Pract 2000;50(460):882-87.

5. Michael M, Schaffer SD, Egan PL, Little BB, Pritchard PS. Improving wait times and patient satisfaction in primary care. J Healthc Qual 2013;35(2):50-59. doi: 10.1111/jhq.12004.

6. Knight A, Lembke T. Appointment zen - Shaping demand and matching capacity. Aust Fam Physician 2014;43(4):234-38.

7. Knight A, Lembke T. Appointments 101 - How to shape a more effective appointment system. Aust Fam Physician 2013;42(3):152-56.

8. Knight A, Lembke T. Appointments - Getting it right. Aust Fam Physician 2011;40(1-2):20-23.

9. Baker $L$, Cordaro $D$, Platt $F$. The first minute. Medical Encounter 2012;26(2):83-84.

10. Marvel MK, Epstein RM, Flowers K, Beckman HB. Soliciting the patient's agenda: Have we improved? JAMA 1999;281(3):283-87.

11. Beckman HB, Frankel RM. The effect of physician behavior on the collection of data. Ann Intern Med 1984;101(5):692-96.

12. Murray M, Berwick DM. Advanced access: Reducing waiting and delays in primary care. JAMA 2003;289(8):1035-40.

13. Dennis S, May J, Perkins D, Zwar N, Sibbald B, Hasan I. What evidence is there to support skill mix changes between GPs, pharmacists and practice nurses in the care of elderly people living in the community? Aust New Zealand Health Policy 2009;6:23. doi: 10.1186/1743-8462-6-23. 